\title{
A Natureza Coletiva do Elo Linguagem-Subjetividade ${ }^{1}$
}

\author{
Silvia Tedesco ${ }^{2}$ \\ Universidade Federal Fluminense
}

\begin{abstract}
RESUMO - O trabalho analisa a natureza do elo entre linguagem e subjetividade. Apoiado em argumentos originados na vertente pragmática de estudos da linguística e da filosofia, o artigo defende a inclusão da abordagem pragmática também no domínio da psicologia da linguagem. Nesta direção, sublinha-se a importância da dimensão coletiva do elo linguagem-subjetividade, capaz de elucidar o plano da gênese constante destes processos. Por fim, propõe-se a noção de estilo-subjetividade, esclarecedora deste elo em sua natureza performativa, produtora de novos sentidos, de realidades e de modalidade subjetivas.
\end{abstract}

Palavras-chave: linguagem; cognição; subjetividade

\section{The Collective Nature of the Pair Language-Subjectivity}

\begin{abstract}
The paper analyzes the connection between language and subjectivity. Based on arguments derived from the pragmatic perspective in linguistic and philosophical studies, we propose the inclusion of a pragmatic approach in the domain of the psychology of language. We then emphasize the importance of considering a collective dimension of the pair language-subjectivity, in order to shed light upon the plan of constant generation of those processes. At last, we introduce the notion of style-subjectivity, which will elucidate the pair languagesubjectivity in its performative nature, producing new senses, realities and subjective modalities.
\end{abstract}

Key-words: language-cognition-pragmatic-subjectivity

Em Arqueologia do saber, Foucault, (1969/1987) nos diz que a verdade ou a causa das enunciações não deve ser procurada na unidade de um sujeito. Seguindo mesma direção G. Deleuze afirma "Não existe enunciação individual nem mesmo sujeito de enunciação" (Deleuze, 1980/1995, p. 17). E acrescenta " A linguagem é dada por inteiro ou não é dada (Deleuze,1986, p. 65). Ou seja, a condição geral dos enunciados exclui a importância da subjetividade como agente e ponto de partida da linguagem.

Ambos pontos de vista divergem da perspectiva corrente nas ciências humanas que insiste em ver na enunciação a manifestação de um sujeito dado, resultado de um conjunto de faculdades, de processos fixos, regulados por leis e princípios invariantes, pelos quais ele pensa e conhece uma realidade pré-existente.

Paralelamente aos autores mencionados, vemos surgir no campo mesmo dos estudos da linguagem, mais especificamente na filosofia da linguagem, a vertente pragmática austiniana, na qual é afirmada que as bases da enunciação encontram-se nas convenções e ritos sociais. O sentido consiste num processo de construção, estabelecido na reciprocidade afirmada entre o universo da linguagem e o mundo movente dos fatos empíricos. Mais uma vez o universo subjetivo desvincula-se da determinação da linguagem. O "eu falo", sujeito da enunciação e origem da linguagem perde o lugar central.

1 Artigo derivado do trabalho apresentado no II Congresso Norte-nordeste, Salvador, 2001.

2 Endereço: Rua Maria Angélica, 741/201 - J. Botânico - Rio de Janeiro, RJ - 22461-150. E-mail: stecesco@ novanet
Observamos serem muitos os estudos na área da linguagem que no século XX, inspirados numa abordagem pragmática, desacreditam as teses psicológicas. Após seu início com C. Morris, encontramos esse modo outro de pensar a linguagem em Ch. S. Pierce, E. Goffman, P. Watzlawick entre muitos outros.

Este trabalho situa-se inicialmente no campo da psicologia da linguagem, mas difere de sua tradição defensora do caráter descritivo ou cognitivo da linguagem. Distante de uma opção teórica ainda refratária às abordagens pragmáticas propomos repensar, à luz destas últimas, a natureza do elo entre linguagem e subjetividade. Mais especificamente, nossa proposta localiza-se na fronteira entre os dois campos de estudo e visa equivocar esse limite, levando esses dois domínios a afetarem-se mutuamente. Nosso objetivo é estabelecer o caráter pragmático do elo, ou seja, sua potência construtora de realidades.

Neste caso, a linguagem não resultará da ativação de sistema de regras invariantes pelo sujeito falante. E, se não optamos por considerar os signos lingüísticos como expressão de uma consciência anterior à palavra, muito menos ainda falaremos de um inconsciente estruturado como uma linguagem. Se à subjetividade é negada a função de fonte ou origem da linguagem, do mesmo jeito rejeitamos a tese do sujeito constituído na linguagem. Não apostamos na simples inversão do vetor de determinação. É na reciprocidade estabelecida entre os termos que reside o potência de engendramento destas duas realidades

A partir do ponto de vista pragmático nos estudos da linguagem, visamos atingir uma pragmática também para a subjetividade. Analisá-la como processualidade e potência de produção de mundos. Longe de referenciais teóricos que 
nos obriguem a pressupor seja constância, seja a preexistência dos termos, sensibilizaremos ambos os componentes às contingências do empírico. Os conceberemos imersos num processo ininterrupto de construção mútua. A linguagem produz subjetividade no mesmo movimento em que é por ela produzida. Afirmamos a existência de um processo de produção recíproca.

Seguir o ponto de vista pragmático nos conduz a conceber a dupla natureza do elo em questão. E com isso o sentido de produção abala-se. Ao falar de produção tratamos, simultaneamente, de dois sentidos que o termo carrega. Entendida como pura repetição, o processo de produção imprime no produto sua própria natureza. O efeito não diverge da direção conduzida pelo processo. Porém, existem momentos em que o processo de produção, no lugar de reproduzir-se no seu efeito, segue direções inusitadas, instala-se como criação, essa estranha modalidade de produção onde o produto diverge das condições de seu engendramento. Ou seja, em sua dupla natureza o elo entre linguagem e subjetividade ora reproduz, ora inventa os dois termos do par.

Para entendermos a primeira modalidade de produção remetemos inicialmente aos estudos de Austin sobre a força ilocutória das palavras (Austin, 1962/1990). Ao falarmos de signos, enfatizamos seu sentido pragmático, sua potência de instauração de realidades. Diferentemente de fazer referência ao mundo, a linguagem intervém sobre ele, engendra os próprios fatos que supostamente descreve. Não mais apartada dos fatos, a linguagem age como eles e sobre eles. No rito do casamento, por exemplo, é a declaração do juiz de paz que transforma solteiros em casados, confere-lhe novos direitos e deveres. A declaração não descreve o fato do casamento, ela o realiza. Do mesmo modo são as palavras contidas no diploma, universitário, por exemplo, que transformam estudantes em profissionais, instituindo-lhes novas obrigações, alterando significativamente, seu estatuto na coletividade. Podemos dizer que a palavra agiu sobre a realidade, produziu um novo estado de coisas. $\mathrm{O}$ ato de intervenção sobre o mundo adere-se à palavra e, uma vez pronunciada, não há como desfazê-lo. Ela deixa sua marca, o selo indiscutível e irredimível de um comando. É neste sentido que, conjuntamente com Austin, definimos a linguagem como ato, isto é, ato de fala.

Mas, quais seriam as condições necessárias ao discurso para o exercício deste poder de produção? Na empiricidade responde-nos Austin. É na ligação com os fatos extralingüísticos que a força ilocutória da palavra se esclarece. As condições de felicidade do ato da fala residem nos ritos e convenções existentes na sociedade. Análise insuficiente diremos, pois neste caso o empírico é identificado a ocorrências factuais já há muito estabilizadas nos discursos e outras práticas vigentes. Parte-se de uma situação dada, ou seja, exploram-se condições já estabelecidas, excluindo-se o processo de constituição destas.

É na conjunção entre teses de Austin e de M. Foucault que encontramos subsídios para o entendimento mais amplo deste processo. Solução que rompe o plano das palavras, assim como o do extralingüístico para também incluir o plano das condições de sua gênese. São, como preferem Deleuze e Guattari, as circunstâncias, tomadas como pressupostos implícitos da linguagem que, sem se confundirem com as palavras, determinam seu sentido pragmático, sua força pro- dutora de real (Deleuze e Guattari, 1980/1995). A partir da leitura de M.Foucault interpretamos esse processo de gênese do sentido como resultado de formações políticas, processos históricos instalados nos dois planos de práticas que atravessam toda a empiricidade: as práticas de dizibilidade e de visibilidade (Deleuze, 1986). A realidade divide-se em duas modalidades de produção de realidades. No primeiro, localizam-se as práticas centradas no uso de signos, isto é, toda e qualquer atividade envolvida com a expressão. No outro, as práticas empíricas que envolvem corpos e coisas. É o plano das ações, das visibilidades. De um lado, os atos, realizações vinculadas às enunciações, de outro, as ações mudas. Da gênese empírica das formas de visibilidade criamse modos de ver e fazer ver; já da produção das formas de dizibilidade, surgem maneiras específicas de falar, regimes de discursos ou de signos, como preferem Deleuze e Guattari (1980/1995). São dois planos de realizações que, embora distintos, não se isentam de intervenções mútuas. Dito de outro modo, as formas do visível e do dizível, agindo em regime de reciprocidade, constroem nosso saber sobre a realidade, respectivamente, os objetos visíveis e os temas a serem tratados nos discursos. A linguagem, portanto, articulada às práticas mudas junto aos corpos instaura realidades.

Entre as realidades produzidas podemos registrar as formas subjetivas. Como nos lembram Rolnik e Guattari, "Um fato subjetivo é sempre engendrado por um agenciamento de níveis semióticos heterogêneos", num entrecruzamento de determinações enunciativas não só sociais, mas também econômicas, tecnológicas, de mídia, entre outros (Guattari e Rolnik, 1993, p. 35). A produção de realidades processa-se na pluralidade de discursos, advindos dos diversos saberes e práticas. É no conjunto de falas que a forma-sujeito constituise como objeto discursivo.

Longe de organizarem uma categoria clara, um conceito com contornos precisos, tal como o pensamento da representação clássica almejava, os conjuntos discursivos estabelecem entre si jogos, cujas regras de produção dos conceitos se instituem na particularidade de cada situação. Apesar de sua intensa heterogeneidade, em certos momentos algo neles os leva numa direção comum, a do objeto a ser produzido. A mesma força pragmática os atravessa e os fazem convergir. Certa convergência entre os discursos é observada, mas nada que se aproxime da identidade. Não é exatamente o mesmo objeto descrito em cada um dos discursos. Não há homogeneidade na maneira de descrevê-lo. A realidade do objeto abriga a dispersão entre as falas, compõe com suas diferenças.

O que significa dizer que a figura-sujeito é entendida como efeito de um feixe de enunciados que, mesmo guardando diversidade, cruzam-se, num dado momento, na direção de um certo tipo de produção. Um conjunto de discursos faz os corpos se comportarem como se eles se acreditassem, se vissem como sujeito, dotado de uma natureza geral regida por princípios e leis constantes. A forma-sujeito surge então em sua homogeneidade forjada, decidida nos pressupostos implícitos do dito, na ligação que as falas estabelecem entre si e o seu exterior, o das práticas de visibilidade. $\mathrm{O}$ efeito principal desta produção é o da extração da enunciação do conjunto coletivo de ditos, presentes no plano do dizível, e a conseqüente emergência do sujeito como agente da fala. 
Uma vez isolada da dimensão coletiva da linguagem, os enunciados organizam-se nos estratos semiológicos hierarquizados, de acordo com certas redundâncias (Guattari, 1978). A extração dos segmentos discursivos instaura, como artifício, a enunciação isolada e justifica a procura de sua fonte num sujeito. O diz-se impessoal é substituído pelo si do sujeito da enunciação. O processo em seu todo tem seu início num conjunto de dizeres, alinhados e redundando um duplo comando: isolamento do enunciado e produção de um si mesmo como ponto de partida. À extração do enunciado do fluxo de discursos segue-se sua captura por uma certa fração de discursos impregnados de determinações pessoais. Ao mesmo tempo em que o isolamento se realiza, o caráter impessoal dilui-se pelo constrangimento de transformar o fluxo de discursos num si mesmo, reflexivo. A enunciação ganha significação pessoal e ponto de partida localizável num eu falante.

Trata-se de um efeito específico do dizer, caracterizado pela produção de repetições, pela produção de regularidades. Entre as regularidades produzidas, portanto, listamos as formas-sujeito.

Mas como dissemos antes, existe na linguagem uma outra modalidade de produção. O processo de produção de diferença. Coexistindo com os processos de produção das formas subjetivas, momento em que a pessoalidade emerge no artifício de falas homogeneizantes, registramos instantes em que o processo de produção bifurca e seus efeitos desviamse da rota esperada e geram, na estranheza desta ruptura, realidades ainda desconhecidas.

Assim com a produção de repetições acontece nos encadeamentos mistos de discursos, o momento de criação na linguagem também depende deste caráter plural e coletivo.

A parceria com Baktin nos parece essencial neste momento. Nos seus achados sobre discurso indireto livre reconhecemos o poder de criação da linguagem.

No domínio da estilística, um certo modo de narração define-se por sua condição paradoxal. Este modo estilístico chama atenção pela dificuldade de entendê-lo a partir de sua forma gramatical. A tônica recai sobre seu caráter híbrido. As análises tributárias da lingüística não conseguem apreender seu sentido. Detectado inicialmente na literatura de Puchikin e com presença freqüente na obra de Dostoievisky, um tipo de enunciação, denominado discurso indireto livre, revela-se como um fenômeno misto da linguagem (Baktin, 1929/1992).

O discurso indireto livre fica melhor compreendido em relação aos dois tipos de discurso tradicionalmente detectados. Chama-se discurso direto livre quando, numa narrativa, a fala de um personagem é relatada fielmente em sua forma inicial. Ou seja, a fala de outrem é repetida sem qualquer alteração. $\mathrm{O}$ discurso direto vem entre aspas e na primeira pessoa. Por exemplo, no monólogo de Fausto, do teatro de Goethe encontramos: Fausto disse: "Ai de mim que estudei filosofia, leis...". Diferentemente, denomina-se discurso indireto, quando o que é dito por alguém é reproduzido segundo o ponto de vista da narrativa. Neste caso, a enunciação é atribuída ao narrador que relata a fala do outro, com suas próprias palavras e expressões. No mesmo exemplo, a transposição poderia ser: "Fausto disse com pesar que havia estudado filosofia, leis..."
O discurso indireto livre tem a particularidade de conter a um só tempo dois tipos de discursos. Ele é formulado pelo narrador, segundo seu ponto de vista, porém, contém palavras e expressões que só poderiam ser ditas pelo personagem. Seguindo o exemplo acima teríamos: "Fausto, ai! Estudou filosofia, leis....". A flexão do tempo e pessoa do verbo revela a presença do narrador, mas a interjeição "ai" só pode ser atribuído ao personagem e não à narrativa. Neste caso o discurso constitui-se num misto entre dois ditos: do personagem e do narrador. $\mathrm{O}$ discurso do personagem intrometeu-se no discurso do narrador, interferiu no sentido da frase, introduzindo uma tonalidade inapreensível pela gramaticalidade. Este tipo de discurso revela heterogeneidade. Tem a particularidade de conter a um só tempo duas enunciações distintas e irredutíveis.

Tal indissociabilidade, novidade desse estilo, explicita um hibridismo que nos interessa particularmente, a saber: a existência de pontos de vista distintos, irredutíveis, porém coexistentes na enunciação.

Ao generalizarmos o discurso indireto livre para toda linguagem extraímos duas consequiências importantes. Uma delas serve à negação da subjetividade como base unificada de enunciações individualizadas. A outra remete à noção de interferência, modo como o autor qualifica a natureza criadora do elo entre as falas. Vejamos cada uma delas.

No discurso indireto livre, as enunciações perdem a nitidez de seus contornos, misturam-se umas nas outras para atrelar seu sentido ao encadeamento infinito de falas. É nesse sentido que se diz que a linguagem é sempre metalinguagem. Tem a si própria como referente. Vai-se do dito ao dito, sem que se possa definir um ponto de partida da linguagem que lhe seja exterior. Sem autoria especificável, as palavras atravessam um número incontável de discursos, difundem-se através de diferentes áreas do social e põem em cena a multiplicidade dos ditos, e desse modo, assinalam em sua enunciação a superposição de várias vozes (Ducrot, 1993). Tal polifonia não constitui um somatório de ocorrências enunciativas que possam ser individualizadas. Sem que seja possível precisar a autoria do evento lingüístico, este se estabelece pelas ligações mútuas entre os ditos. A manifestação é antes coletiva e o enunciado individualizado é sempre derivado, fruto da ação de destacar um componente do conjunto de enunciados vigentes numa dada sociedade. É nesse sentido que, para Baktin (1929/1992), toda enunciação por mais completa que seja é apenas uma fração extraída de uma corrente ininterrupta de falas.

A segunda conseqüência de nossa parceria com Baktin deve-se à revisão sofrida pela noção de interferência para aproximá-la de um efeito de variação ou de criação.

Nas palavras de Baktin, o discurso do personagem interfere no discurso do narrador, introduzindo descompasso na significação. O sentido das palavras não se completa, pois não há unificação possível entre os pontos de vista coexistentes. No lugar do entendimento fácil, a experiência é de estranheza. Isto porque o sentido mantém-se indecidível, alojado no embate entre a diferença própria a cada enunciação. A interferência entre os discursos distintos age, na verdade, provocando a quebra de compreensão. E o não-sentido gerado pelo hibridismo da linguagem tem como efeito principal a exigência da busca de novas significações. 
Trata-se ainda de ver a linguagem como coletivo de enunciações, tal como descrevemos anteriormente nas formações discursivas, no seu poder de produção de repetições. Porém, neste caso, o coletivo, a rede discursiva assume outra natureza. Diferente de produzir repetições, redundâncias discursivas, de convergir na produção de uma realidade comum, o caráter disperso do conjunto produz atrito, investe na divergência entre falas coexistentes e assim, mantém em suspenso a finalização do sentido. No lugar da significação esperada surgem séries infinitas e proliferantes de novas significações. As realidades criadas pelas palavras, neste caso, divergem da ordem estimada dos fatos, faz emergir o acontecimento, rupturas na ordem geral estabilizada.

Neste momento, cabe nos perguntarmos como esse outro sentido plural e divergente afeta a subjetividade. Dito de outro modo, indagamos sobre os efeitos do elo entre o sentido desviante dos signos e a subjetividade.

Quando a fala expõe seu caráter impessoal, deixa vazar discursos menos redundantes, rumores com sentido indefinido, pervertendo modos de subjetivação modelizantes. A produção criadora da linguagem ao apoiar-se na dispersão irredutível do sentido não remete à unidade do sujeito falante. A enunciação perfeitamente individualizada dá lugar à assinatura plural. No contato com a heterogeneidade da linguagem, a unidade fictícia do eu fragmenta-se, abandona os modos de subjetivação repetidora, serializantes e ativa sua natureza plural, em deriva, engajada na criação de novos sentidos, isto é, na construção de novas formas de dizer e experimentar a vida. Ou seja, como efeito do conjunto paradoxal de dizeres é dado à subjetividade viver novas modalidades de pensar, de sentir, de perceber o mundo. O sentido bifurcante dos signos prolifera modos de subjetivação singularizantes.

Neste ponto, apostando na parceria com Baktin, Austin, Foucault e em especial com G. Deleuze e F. Guattari, forçaremos o redirecionamento das pesquisas da psicologia da linguagem a fim de incluirmos o estudo da dimensão de produção criadora dos signos. Para tal, propomos a noção de estilo-subjetividade. Neste caso, elo entre subjetividade e linguagem expressa o processo pelo qual os dois termos afetam-se mutuamente na geração de novos sentidos, de novas modalidades subjetivas. A partir deste momento explicitaremos a dimensão criadora do elo entre linguagem e subjetividade através da noção de estilo.

Para isto, rejeitamos a definição tradicional de estilo que o concebe como a extraordinária habilidade de aplicação das regras da escrita. Ao contrário, para nós, estilo não envolve submissão à sintaxe e sim um ato de resistência. Nele o uso do código se presta a transgressões. No lugar de significações fáceis, imediatamente reconhecíveis, o estilo introduz descompasso na compreensão. O estilo pode fazer o texto escapar do código sem, no entanto afastar-se do universo do sentido. Elimina a obviedade das significações, desvia a linguagem de sua rota familiar, promovendo signos-enigmas, só apreendidos através de um exercício infindável de busca de significações. O estilo compromete a univocidade do texto em nome da coexistência de múltiplos sentidos e da estranheza feliz que ela comporta.

Seleciono algum exemplos na literatura para facilitar a compreensão. Em Guimarães Rosa encontramos a composição "Sussuruído" (Rosa, 1979), cujo sentido oscila entre o som inaudível de um sussurro e a perturbação causada pelo ruído, sem permitir decisão conclusiva. A divergência interna ao signo impede a síntese do sentido para manter vivo e eterno o processo de sua decifração.

Em Proust detectamos uma outra modalidade de estilo, onde não ocorrem rupturas da sintaxe ou do léxico. Ao descrever o personagem Albertina, por exemplo, ressalta a decalagem entre a confiança e a suspeita de ciúme que seu rosto inspira. (Deleuze, 1976/1987). O texto constrói-se a partir de imagens paradoxais. Na ausência de unificação possível o sentido segue múltiplas direções.

O estilo também pode introduzir o impasse na significação através da sonoridade da voz: a entonação, o ritmo, velocidade e altura entre outros. Observam-se como certas palavras são pronunciadas de modo quase inaudível, outras têm sua acentuação duplicada, alterando muitas vezes o resultado do que é dito e envolvendo a equivocação de sentido.

Enfim, os procedimentos estilísticos, em suas inúmeras formas de manifestação, têm por regra de funcionamento produzir efeitos de atrito, disruptores das unidades de significação.

Nestes momentos, ao mesmo tempo em que a linguagem toma direções indeterminadas, trazendo à cena universos de significação ainda a serem construídos, a forma subjetiva segue novos rumos, bem longe de sua aparente unidade. Pois tal procedimento, ao transparecer sua condição impessoal, coletiva, bloqueia as repetições do eu e deixam vazar discursos menos redundantes, rumores com sentido mais indefinido, pervertendo processos de subjetivação modelizantes. Através dos atos de estilo-subjetividade é dado à linguagem e à subjetividade tocar o acontecimento, inaugurar o não sentido proliferante de novos mundos.

Contra todo personalismo, psicológico ou lingüístico, eles [os acontecimentos] promovem uma terceira pessoa, a não-pessoa ou o pronome impessoal, no qual nós nos reconhecemos nós mesmos ou reconhecemos nossa comunidade, bem mais do que nas trocas vazias entre um Eu e um Tu." (Deleuze, 1989, p. 90)

A proposta de estudo da noção de estilo-subjetividade é produzir um desvio nos estudos da psicologia da linguagem, preocupados apenas com as invariâncias de uma faculdade lingüística. Assim como o gerativismo chomskiano (Chomsky, 1980/1981,1992) descreve uma competência lingüística, a pragmática de Kebrat-Orecchione (1988) fala de uma competência retórico-pragmática, nós propomos o estudo da competência estilística, essa modalidade de produção criadora realizada junto à linguagem na qual a subjetividade transborda de seus contornos realizando o processo de criação de si que melhor a define.

\section{Referências}

Austin, J.L (1990) Quando dizer é fazer.(D.M.Souza Filho trad.) Lisboa, Artes Médicas.(trabalho original publicado em 1962)

Baktin, M. (1992) Marxismo e filosofia da linguagem. (M. Lahud \& Y.F. Vieira trad.) São Paulo, Hucitec. (trabalho original publicado em 1929)

Chomsky, N. (1981) Regras e Representações.(W.Averbug,P.H. Britto,R.Bustamente trad.).Rio de Janeiro, Zahar. (trabalho original de 1980) 
Chomsky, N. (1992) A minimalist program for linguistic theory. MIT Working Papers, Cambrigde.

Deleuze, G. (1987) Proust e os signos. (A.C. Piquet R. Machado, trad.) Rio de janeiro, Forense.(trabalho original publicado em 1976)

Deleuze, G. (1986) Foucault. Minuit, Paris.

Deleuze, G. (1989) Um concept philosophique. Cahiers Confrontation, 20, 89-90.

Deleuze, G. \& Guattari, F. (1995) Mil Platôs.v.2, (A L. Oliveira trad.) Rio de Janeiro, Ed. 34. (trabalho original publicado em 1980)

Ducrot, O. (1993) Dire et ne pas dire. Paris, Hermann.
Foucault, M. (1987) A arqueologia do saber. (L.F. Baeta Neves trad.) Rio de janeiro, Forense.(trabalho original publicado em 1969)

Guatari, F. (1978) La politique de l'énonciation. Semiotexte I, 3, 9- 17 .

Guattari, F. \& Rolnik, S.(1993) Micropolíticas:Cartografias do desejo. Petrópolis, Vozes.

Rosa, J.G. (1979) Grande sertões: veredas. Rio de Janeiro, José Olympio.

Kerbrat-Orecchioni, C. (1988) L'enonciation, Paris, Arman Colin. 